Sinval Zaidan Gama

\title{
NOVO PERFIL DO ENGENHEIRO ELETRICISTA NO INÍCIO DO SÉCULO XXI
}

\section{Tese de Doutorado}

Tese apresentada ao Programa de Pós-graduação em Engenharia Elétrica do Departamento de Engenharia Elétrica da PUC-Rio como parte dos requisitos parciais para obtenção do título em Engenharia Elétrica da PUC-Rio.

Orientador: Prof. Marcos A. da Silveira

Volume I

Rio de Janeiro

Dezembro de 2002 
Todos os direitos reservados. É proibida a reprodução total ou parcial do trabalho sem autorização da universidade, do autor e do orientador.

\section{Sinval Zaidan Gama}

Graduou-se em engenharia elétrica na Universidade Federal de Pernambuco em 1977 e pós-graduado pela Universidade Federal de Minas Gerais em 1982. Cursou Gestão de Empresas pela George Washington University em 1992, Aperfeiçoamento de Executivos pela Universidade Estadual de São Paulo em 1995 e MBA em Mercado Financeiro e Capitais pelo Instituto Brasileiro de Mercado de Capitais em 1994. Desenvolveu junto a UFPe, UFSC, UNB e PUCRio, os primeiros mestrados profissionais em Engenharia para as empresas do sistema Eletrobrás. Participou em diversos eventos do REENGE no Brasil e missões no exterior sobre função do Engenheiro. Foi executivo responsável pela interface Empresa/Universidade, diretor de Engenharia e presidente de empresas do setor elétrico.

Ficha Catalográfica

Gama, Sinval Zaidan

Novo perfil do engenheiro eletricista no início do século XXI / Sinval Zaidan Gama; orientador: Marcos A. da Silveira. - Rio de Janeiro : PUC, Departamento de Engenharia Elétrica, 2002.

$$
\text { [10], } 621 \text { p. ; } 30 \mathrm{~cm}
$$

Tese (doutorado) - Pontifícia Universidade Católica do Rio de Janeiro, Departamento de Engenharia Elétrica.

Inclui referências bibliográficas.

1. Engenharia elétrica - Teses. 2. Educação profissional. 3. Perfil de formação. I. Silveira, Marcos A. da. II. Pontifícia Universidade Católica do Rio de Janeiro. Departamento de Engenharia Elétrica. II. Título. 


\title{
NOVO PERFIL DO ENGENHEIRO ELETRICISTA NO INÍCIO DO SÉCULO XXI
}

\begin{abstract}
Tese apresentada ao Programa de Pós-graduação em Engenharia Elétrica do Departamento de Engenharia Elétrica da PUC-Rio como parte dos requisitos parciais para obtenção do título em Engenharia Elétrica da PUC-Rio.
\end{abstract}

Prof. Marcos Azevedo da Silveira Orientador Departamento de Engenharia Elétrica - PUC-Rio

Prof. José Carmelo Braz de Carvalho

Departamento de Educação - PUC-Rio

Prof. Reinaldo Castro Souza

Departamento de Engenharia Elétrica - PUC-Rio

Prof. Ruderico Ferraz Pimentel Departamento de Engenharia de Produção - UFF

Prof. Ricardo Bernardo Prada Departamento Engenharia Elétrica - PUC-Rio

Prof. Luiz Antônio Meirelles Departamento de Engenharia de Produção - PUC-Rio

Wladimir Pirró e Longo Departamento de Engenharia Mecânica - UFF

Coordenador Setorial Coordenador (a) Setorial do Centro Técnico Científico - PUC-Rio 
NADA ESTIMO MAIS, ENTRE TODAS AS COISAS QUE NÃO ESTÃO

EM MEU PODER, DO QUE CONTRAIR UMA ALIANÇA DE AMIZADE COM HOMENS QUE AMEM SINCERAMENTE A VERDADE.

ESPINOSA

A FAMÍLIA, CÉLULA MATER. 


\section{Agradecimentos}

Este projeto só foi possível pelo apoio da ELETROBRÁS, tanto no financiamento direto do curso do doutorando, quanto de importantes etapas de apoio: bolsa de mestrado para pesquisador, pesquisa de campo, participação de acadêmicos em seminários e no patrocínio de seminários regional e nacional.

As empresas do setor elétrico ELETROBRÁS, CELPE, Furnas, CHESF, ELETRONORTE, ELETROSUL, CEPEL, ELETRONUCLEAR, Light, ONS e CERJ, por intermédio de engenheiros, e as Universidades Federal do Rio de Janeiro, Federal Fluminense, Estadual do Rio de Janeiro, PUC-Rio, Veiga de Almeida, Santa Úrsula e Gama Filho, por intermédio de professores, tiveram substancial contribuição na pesquisa de campo.

O Governo Britânico, através do British Council do Rio de Janeiro, exerceu importante papel ao entender a importância do projeto e apoiar com a vinda de acadêmicos e executivos do Reino Unido para participação em seminários e encontros técnicos no Brasil, bem como na recepção de missões brasileiras naquela comunidade.

A Pontifícia Universidade Católica do Rio de Janeiro foi durante todo o período, um ambiente fértil, acolhedor, inovador e vibrante, que motivou e encorajou o desenvolvimento desta pesquisa.

O forte, constante e sempre renovado espírito de entusiasmo (a etimologia da palavra é divina) do orientador Professor Doutor Marcos da Silveira foram indispensáveis em todo o processo. Embora os dicionários descrevam orientador de forma simples, ressalto que tive mais que uma orientação, tive na prática 
exemplo daquilo que esperava de um tutor universitário: apresentação de novas abordagens para problemas existentes, entendimento das diferentes visões das partes envolvidas, visão multidisciplinar, incentivo para a pesquisa em diferentes campos e uso de fatos e dados que comprovem uma teoria. As limitações do "viés" acadêmico do doutorando, que em todo o período foi compensado com outros esforços adicionais, tiveram no orientador seu maior suporte.

Os Professores Doutores da PUC-Rio, José Carmelo, Reinaldo Souza e Ricardo Prada, em diversos períodos do doutorado, tiveram papel relevante e importante.

O agradecimento final vai para as minhas filhas Fabiene, Sandra e Renata que abriram mão de diversos momentos de convivência familiar para que fosse possível desenvolver o trabalho, pelo interesse e participação, e nos momentos de dificuldades pelo incentivo adicional e especialmente a Sandrinha e o amigo Renan Taira pela importante ajuda na formatação final do documento. 


\section{Resumo}

Gama, Sinval Zaidan; da Silveira, Marcos Azevedo (Orientador). Novo Perfil do Engenheiro Eletricista no Início do Século XXI. Rio de Janeiro, 2002, 631p. Tese de Doutorado - Departamento de Engenharia Elétrica, Pontifícia Universidade Católica do Rio de Janeiro.

Este trabalho contempla o estudo das propostas REENGE para o perfil de formação do engenheiro, analisando sua fundamentação diante das mudanças estruturais do setor elétrico brasileiro; e pesquisa as necessidades de formação do engenheiro eletricista na visão do mercado de trabalho do mesmo setor, através de pesquisa de campo.

Baseado no confronto das opiniões assim levantadas, o trabalho estabelece um perfil de formação do engenheiro eletricista, informado pela visão de futuro da academia e pelas necessidades dos integrantes do mercado de trabalho, fornecendo subsídios para que as diversas instituições de ensino superior estabeleçam seus perfis de formação particulares, conforme estabelecem as Diretrizes Curriculares Nacionais do Curso de Engenharia.

O perfil de formação indicado não se restringe a uma lista de conteúdos, e sim a uma abordagem diferente de transmissão de Saberes, onde um conjunto de conhecimentos, habilidades e atitudes necessários para as competências desejáveis é indicados.

\section{Palavras-chave}

Educação profissional, perfil de formação, engenharia elétrica 


\section{Abstract}

Gama, Sinval Zaidan; da Silveira, Marcos Azevedo (Orientador). New Profile for an Electric Engineer in the Beggining of the $21^{\text {st }}$ Century. Rio de Janeiro, 2002, 631p. Doctor Thesis - Electric Engineer Departament, Pontificates Universidade Católica do Rio de Janeiro.

This work covers the studies of the REENGE proposals for knowledge backgroundof an engineer background, analyzing its statements on the electric sector structural changes; and it focus the background needs for an electric engineer using the market view of the same sector, throughout field research.

Based on the opinions check that came up, the work establishes a background profile for the electric engineer, formed by the academy future vision and the needs of the integrants of the labor market, giving support for many higher education institutions to establish its particular profile background, as the national Curriculum directions for the electric engineer course are established.

The background profile indicated is not limited to a list of content, it is a different knowledge transference approach, in which knowledge, skills and attitudes for the necessary desired competence are indicated.

\section{Keywords}

Profissional education, formation profile, electrical enginnering 


\section{Sumário}

1. Introdução 11

2. Pressupostos, o novo contexto e a internacionalização da indústria de energia elétrica no Brasil

3. Os problemas existentes: no âmbito da industria de energia elétrica e os primeiros passos na busca da solução, e no âmbito da academia e os esforços para a consolidação da formação de novos engenheiros - o REENGE e ações implementadas

4. A conjugação dos esforços, abordagem e visão única da indústria de energia elétrica e da academia na definição do perfil do novo engenheiro eletricista e a relevância do problema

5. O referencial teórico utilizado para a conceituação do novo perfil e a metodologia utilizada para coleta de dados

5.1. Referencial teórico

5.2. Pesquisa de campo

5.3. Teste de validação - Projeto piloto em Pernambuco

5.4. Pesquisa no Rio de Janeiro 46

5.5. O estado da arte 47

6. Avaliação dos resultados da pesquisa 49

6.1. Caracterização do engenheiro entrevistado 49

6.1.1. Caracterização da graduação 52

6.1.2. Caracterização da pós-graduação 54

6.1.3. Necessidade de atualização profissional 56

6.1.4. Emprego e atividades atuais $\quad 57$

6.1.4.1. Cargo/função que ocupa 60

6.1.4.2. Tarefa principal que executa 61

6.2. Necessidade de formação (pesquisa espontânea) 62

6.2.1. Conhecimentos 65

6.2.2. Matérias/cursos de que nunca sentiu falta na vida 70 profissional

6.2.3. Matérias/cursos de que sentiu falta na vida profissional 71

6.2.4. Matérias que deveriam ser incluídas na graduação 72

6.2.5. Matérias que deveriam ser estudadas na pós-graduação, depois de alguma experiência $\quad 74$

6.3. Sugestões para otimização do atual sistema de formação do engenheiro elétrico

6.4. Habilidades requeridas $\quad 77$

6.4.1. Gerenciais e administrativas $\quad 77$

6.4.2. Pessoais e interpessoais $\quad 77$

6.4.3. Técnicas 78 
7. Conclusões e sugestões 81

8. Anexos 93

8.1. Elenco de necessidade das empresas 93

8.2. Conjunto de conhecimentos necessários aos engenheiros das empresas

8.3. Análise dos conhecimentos do GCOI 98

8.4. Workshop do hotel Glória 103

8.5. Quadro de habilidades para o mundo do trabalho 113

8.6. Questionário da pesquisa do projeto piloto em Pernambuco 114

8.7. Questionário da pesquisa do Rio de Janeiro 123

8.8. Tabulação das respostas da pesquisa do Rio de Janeiro 124

8.9. A visão internacional 609

9. Referências bibliográficas $\quad 627$ 